\title{
Economic and environmental assessment of small and decentralized wastewater treatment systems
}

\author{
R. Nogueira ${ }^{\mathrm{a}^{*}}$, A.G. Brito ${ }^{\mathrm{a}}$, A.P. Machado ${ }^{a}$, P. Janknecht ${ }^{\mathrm{b}}$, J.J. Salas ${ }^{\mathrm{c}}$, L. Vera ${ }^{\mathrm{d}}$, G. Martel ${ }^{\mathrm{d}}$ \\ ${ }^{a}$ IBB-Institute for Biotechnology and Bioengineering, Centre of Biological Engineering, University of Minho, \\ Campus de Gualtar, 4705-057 Braga, Portugal \\ Tel.+351 253604410; Fax+351253678986; emails: regina@deb.uminho.pt, agbrito@deb.uminho.pt \\ ${ }^{b}$ Stadtwerke Düsseldorf AG-Wasserwirtschaft und Technik Himmelgeister Landstrasse 1 \\ 40589 Düsseldorf, Germany, email: pjanknecht@swd_ag.de \\ 'Department of Applied Research, New Water Technologies Centre (CENTA), \\ Avda. Américo Vespuccio 5-A, 2ª, Módulo 10, 41092 Seville, Spain, email: jjsalas@centa.org.es \\ ${ }^{d}$ Water Department - Instituto Tecnológico de Canarias (ITC), Playa de Pozo Izquierdo, \\ s/n,35119 Santa Lucía, Las Palmas, Spain, emails: gmartel@itccanarias.org,lvera@itccanarias.org
}

Received 14 April 2008; Accepted in revised form 5 August 2008

\section{A B S T R A C T}

The aim of the present work was the assessment of economic and environmental aspects of decentralized energy-saving wastewater treatment systems. The formulated investment and operation cost functions were adjusted by a power law function. The different wastewater systems serving population settlements between 50 p.e. and 250 p.e., presented associated investment costs varying from $€ 400 /$ p.e. to $€ 200 /$ p.e. and annual operation costs in the range of $€ 70 /$ p.e. $-€ 20 /$ p.e., respectively. A life cycle analysis approach was used to compare the environmental impact of alternative wastewater treatment systems. The assessment was focused on two energy-saving systems (constructed wetland and slow rate infiltration) and a conventional one (activated sludge process). Low environmental impact of energy-saving wastewater treatment systems was demonstrated, being the most relevant the global warming indicator. Options for reduction of life cycle impacts were assessed including materials used in construction and operation lifetime of the systems. A $10 \%$ extension of operation lifetime of constructed wetland and slow rate infiltration systems lead to a $5 \%$ and $7 \%$ decrease in the abiotic depletion indicator, respectively, and to a $1 \%$ decrease in $\mathrm{CO}_{2}$ emissions in both systems. Replacing steel with HDPE in the activated sludge tank resulted in a $1 \%$ reduction in $\mathrm{CO}_{2}$ emission and $1 \%$ in the abiotic depletion indicator. In the case of the Imhoff tank a $1 \%$ reduction in $\mathrm{CO}_{2}$ emissions and $5 \%$ in abiotic depletion indicator were observed when concrete was replaced by HDPE. Therefore, considering the huge potential of energy saving wastewater treatment systems, the overall environmental impact of such design alternatives should not be discarded.

Keywords: Wastewater treatment; Slow rate infiltration; Constructed wetland; Cost function; Life cycle assessment

\section{Introduction}

Eco-efficiency is characterized by a continuous effort towards the improvement of economical and environ-

* Corresponding author. mental values and a long-term need for sustainability. Therefore, the goals for wastewater treatment systems are moving beyond the protection of human health and aquatic ecosystems to include minimization of the loss of scarce resources, reduction of the use of energy and water, reduction of waste generation and recycling of 
nutrients [1]. The directive 91/271/CE of the Council from May 1991 and the subsequent initiatives concerning municipal wastewater treatment are important guidelines for water resources protection in the European Union. Currently, most of the large scale problems are being solved or addressed and the challenge concerns wastewater treatment of communities located in rural areas. Under these conditions, it is hardly feasible, from an economical point of view, to build sewer systems and centralized wastewater treatment plants. Therefore, it is a priority the implementation of decentralized solutions and a pertinent question arises then concerning the selection of the most appropriate design. Two technological options are available for such purpose, the so-called natural or energy-saving wastewater treatment systems and the intensive treatment systems.

The energy-saving technologies are those that simulate the conditions of natural wetlands (e.g. constructed wetlands), the processes which occur in rivers and lakes (e.g. artificial lagoons) and the soil ecosystem (e.g. slow rate infiltration) [2]. Therefore, such wastewater treatments systems show different performances, result in different impacts in the environment and have different associated costs. Cost functions are essential to produce estimations based on a reduced number of variables, easily identifiable and quantifiable. Based on investment and operation costs, such tool should enable a first pre-selection among the existing wastewater treatment solutions. The life cycle assessment methodology has been used to explore the sustainability of wastewater systems, allowing a comparison of different technical solutions in terms of the estimated environmental loads [3-5]. Wastewater treatment in rural areas requires decentralized systems and different options and technologies are available for such purpose.

The aim of the present work was the assessment of economic and environmental aspects of decentralized energy-saving wastewater treatment systems. The specific objectives were: (i) to develop cost functions focused on energy-saving systems and (ii) to compare alternative wastewater treatment systems for small and decentralized rural communities. The work was carried out within the frame of DEPURANAT - sustainable wastewater management in rural areas, an EU project co-financed by Interreg IIIB Atlantic Arc Program. The DEPURANAT project partners included Canaries Islands (Spain), Andalusia (Spain) and Minho (Portugal).

\section{Methods}

The methodology applied in the present work contemplated several phases as depicted in Fig. 1. The layout of the twelve energy-saving wastewater treatment systems, constructed or upgraded under DEPURANAT project, included a pre-treatment for suspended solids
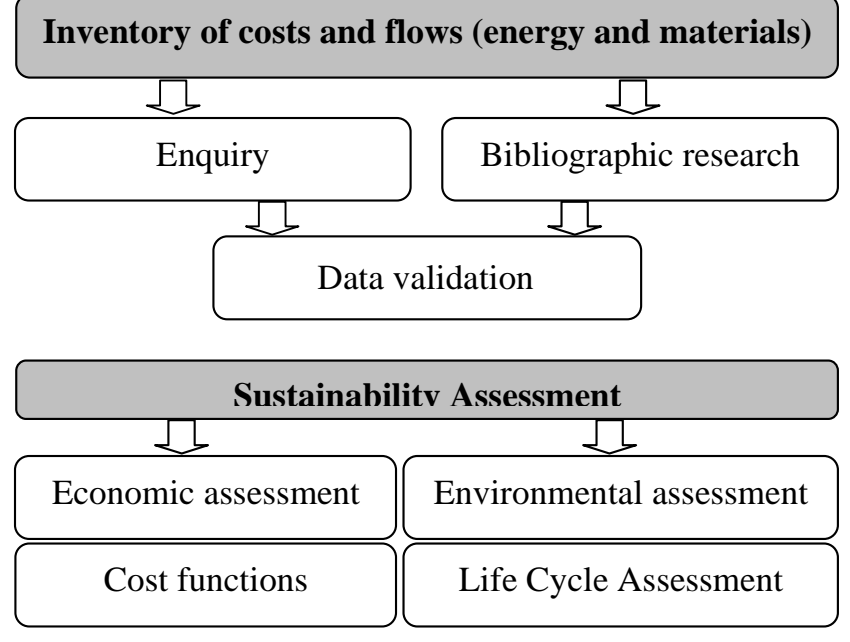

Fig. 1. General methodology.

removal (bar screening), an anaerobic biological process provided by a septic tank or an Imhoff tank, and a secondary treatment for wastewater polishing. The secondary treatment is carried out by different options, as follows: vertical- and horizontal-flow constructed wetland, free-water-surface constructed wetland, combination series/parallel of constructed wetlands, and slow rate infiltration. More detailed information about the systems is described in [6].

The formulation of cost functions of energy-saving wastewater treatment systems consisted in the assessment of the relationship between the dependent variables $Y_{1}\left(Y_{1}=\right.$ investment cost/served population $)$ and $Y_{2}\left(Y_{2}=\right.$ annual operation cost/served population) and the independent variable $X(X=$ served population $)$ by regression analysis with a level of significance of $5 \%$ using the statistical software tool SPSS version 14.0 [6]. The mathematical functions used were inverse, logarithmic, power and quadratic. The quality of the adjustment was evaluated by the determination coefficient $\left(R^{2}\right)$ and also through residues analysis to check if they presented an approximately normal distribution.

Life cycle assessment (LCA) is a quantitative methodology that evaluates the effects that a system has on the environment over the entire period of its life cycle. The LCA study carried out in the present work and described in detail elsewhere [7] followed the ISO 14040:1997 series and comprised an inventory analysis and an impact assessment of resources and emissions associated with the wastewater treatment systems. Three wastewater treatment systems were included in the scope of the present LCA study:

- A slow rate infiltration system serves a population equivalent of 40 p.e. in winter and 120 p.e. in summer and processes a flow rate of $5 \mathrm{~m}^{3} / \mathrm{d}$ in winter and $15 \mathrm{~m}^{3} / \mathrm{d}$ in summer. The system occupies an area of 
$2000 \mathrm{~m}^{2}$ and the biomass is Populus euroamericana (40) and Eucaliptos camaldulensis (214). The irrigation is provided by a PE piping system. The biomass is harvested each 5 years and the wood shredded in order to be used to produce pulp;

- A constructed wetland system serves a population equivalent of 120 p.e. and processes a flow rate of 15 $\mathrm{m}^{3} / \mathrm{d}$. The system comprises a vertical flow, $317 \mathrm{~m}^{2}$, and a horizontal flow, $277 \mathrm{~m}^{2}$, constructed wetlands in series both with Phragmites australis. An Imhoff tank is used as pre-treatment. The following materials are used: i) geotextile lining, ii) gravel (support), iii) PE, PP and PVC (piping), and iv) concrete and PVC (Imhoff tank). The biomass requires annual culling and the green waste is sent to a landfill. The sludge accumulated in the Imhoff tank is removed every 10 years and is used as soil amendment;

- An activated sludge system (extended aeration) serves a population equivalent of 500 p.e. and processes a flow rate of $60 \mathrm{~m}^{3} / \mathrm{d}$. The activated sludge tank was constructed in inox steel AISI 306 and has two surface aerators, functioning each $11 \mathrm{~h} / \mathrm{d}$. The sludge is purged from the settling area and is used as soil amendment.

The wastewater treatment system function is to produce a treated effluent that can be discharged in surface waters according to the legal standards stated by the Portuguese authorities $(40 \mathrm{mg} / \mathrm{L}$ as BOD, $150 \mathrm{mg} / \mathrm{L}$ as COD, $15 \mathrm{mg} / \mathrm{L}$ of ammonium, and $10 \mathrm{mg} / \mathrm{L}$ of phosphorous), the functional unit was one population equivalent (p.e.), and the period of comparison was set at 10 years. Fig. 2 depicts the system boundaries defined in the present study. The materials used in the construction phase were considered to last for the whole life cycle of the systems, no replacement being considered for such purpose. The ultimate disposal site for the disassembled materials and wastes was assumed to be a landfill. The excess sludge purged from the treatment process was applied as soil amendment and the phosphorus and nitrogen avoided in land farming was calculated.

The inventory analysis comprised production of components (equipments and accessories), construction and assembly, operation and maintenance, and dismantling and final disposal of the wastewater treatment components.
In the present LCA study SimaPro 7 software was used as a database for the inventory on resources' consumption and environmental emissions. The environmental impact assessment comprised two steps: classification and characterization. In the classification step, all emissions were sorted into impact categories according to their environmental effects. Certain emissions were included in more than one impact category, as is the case of NOx that contributed to acidification and eutrophication. Subsequently, emissions within each impact category were aggregated using characterization factors that compared the effect of a specific emission with that of a reference emission [8]. The characterization method chosen was the CML 2 BASELINE 2000. The impact categories considered in the present study and the respective reference emissions, in brackets, were abiotic depletion $(\mathrm{Sb})$, acidification $\left(\mathrm{SO}_{2}\right)$, and global warming $\left(\mathrm{CO}_{2}\right)$. Resources consumption is directly related with the impact categories abiotic depletion and global warming and included energy (fossil fuel and electricity), materials used in construction of wastewater treatment components (concrete, gravel plastics, metals), and raw materials used as inputs to materials' production. Environmental emissions to air contributed to impact categories acidification and global warming and comprised mainly carbon dioxide and monoxide, nitrogen dioxide and oxides, sulfur oxide and dioxide, and particles.

\section{Results and discussion}

One focus of the present study was on the economics of twelve energy-saving systems used for wastewater treatment in rural areas with communities up to 250 p.e. The investment and annual operation costs depicted in Fig. 3 and Fig. 4, respectively, present a decreasing tendency with the increase of the served population. The wastewater treatment systems serving communities between 50 p.e. and 250 p.e. present associated investment costs varying from $€ 400 /$ p.e. to $€ 200 /$ p.e. and annual operation costs varying from $€ 70 /$ p.e. to $€ 20 /$ p.e (data from 2006). The performance of energy-saving wastewater treatment systems has been studied intensively in the last decades, yet information regarding investment and operation costs of these systems is scarce in literature. Salas [9] reported investment costs of constructed wet-

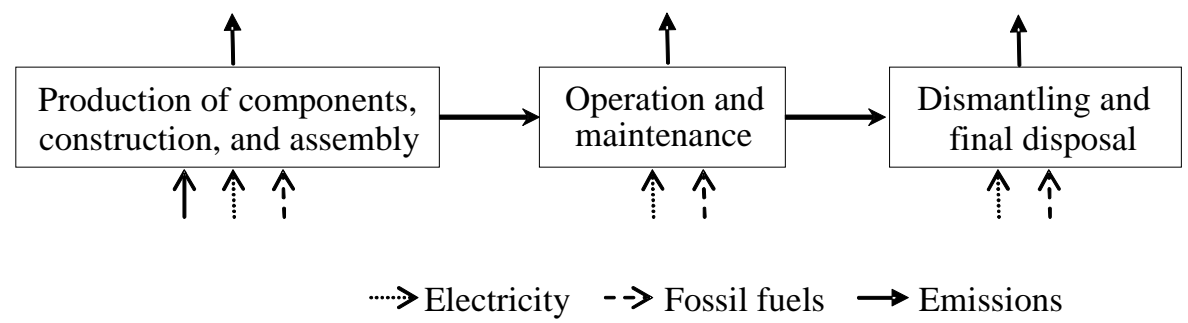

Fig. 2. Boundaries of life cycle study. 


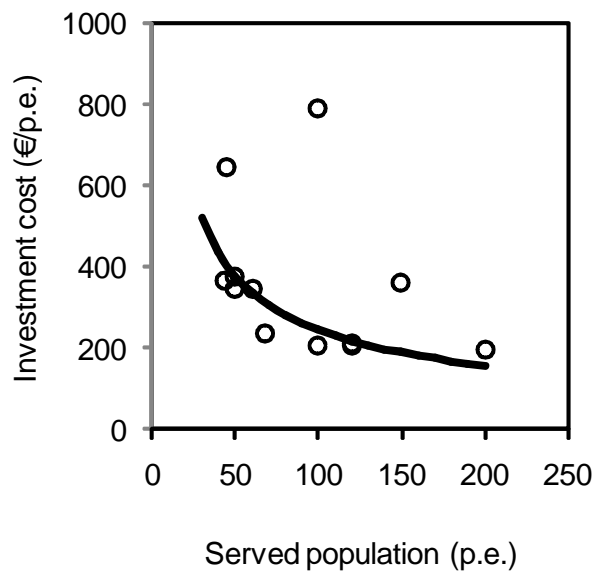

Fig. 3. Investment cost as a function of served population $\left(R^{2}=0.72\right)$.

lands in the Andalusia region (Spain) between $€ 400 /$ p.e. and $€ 250 /$ p.e., for a served population in the range of 150-250 p.e. A study carried out by l'Office Internacionale de $1^{\prime} E a u$ [10] in France indicated an investment cost of $€ 530 /$ p.e. for a constructed wetland serving a population with 100 p.e. Also, Rousseau [11] reported investment costs of constructed wetlands in Belgium between $€ 480 /$ p.e. and $€ 120 /$ p.e. In this context, the investment costs obtained in the scope of DEPURANAT project (data from 2006) are encompassed by the ones described in literature, although the costs are not based on the same year.

Though the current study is focused on energy-saving wastewater treatment technologies, it is adequate to establish a comparison with intensive technologies. Studies performed in Spain [9] and France [12] show that the investment costs of energy-saving systems (lagoon, slow rate infiltration, and constructed wetland) are, in general, lower than those of intensive systems (extended aeration, bio-disc, and trickling filter). The exploitation of energy-saving systems is, in general, less expensive than the operation of intensive systems, in particular concerning the energy costs but, also, the sludge processing costs.

The development of cost functions is crucial in predesign studies as it allows the preparation of simplified budgets based on a reduced number of variables which are easily identifiable and quantifiable. Cost functions of investment and operation (Figs. 3 and 4) were both modeled using the power law because a higher $R^{2}$ value was obtained $(>0.70)$ in comparison with the $R^{2}$ values obtained with other mathematical functions (inverse, logarithmic, and quadratic).

Another focus of the present study was to evaluate the environmental aspects of energy-saving (constructed wetland and slow rate infiltration) and intensive (activated sludge) wastewater treatment systems serving a population with a size of the same order of magnitude.

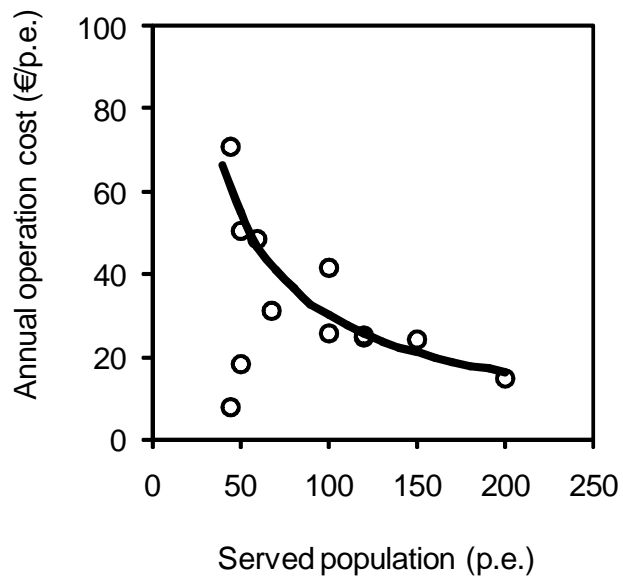

Fig. 4. Annual operation cost as a function of served population $\left(R^{2}=0.85\right)$.

Firstly an inventory analysis of resources and emissions of the different wastewater treatment systems was carried out. Afterwards, all emissions were sorted into impact categories according to their environmental effects. Finally, emissions within each impact category were aggregated using characterization factors that compared the effect of a specific emission with that of a reference emission. Fig. 5 presents the inventory results per impact category expressed in relation to a functional unit of 1 p.e.

In the present study the materials used in higher amounts for construction were concrete (e.g., Imhoff tank), plastics (piping in all treatment systems and geotextile membrane in the lining of the constructed wetland), and steel (activated sludge tank). All such items contributed to the impact category abiotic depletion because they use raw materials in its production and to the impact category global warming since energy consumption is used in the production process. The activated sludge system presents the highest impact in both categories.

The energy usage of constructed wetland and slow rate infiltration systems is similar because both systems require a very low input. On the contrary, the activated sludge has much higher energy requirements because of the aeration equipment ( $22 \mathrm{~h} / \mathrm{d}$ operation). These results agree with those reported by Dixon et al. [5]. Energy usage (fossil fuel and electricity) is the main contributor to the impact categories abiotic depletion and global warming which justifies the fact that activated sludge presents a higher impact in both categories.

The $\mathrm{CO}_{2}$ emissions are directly related to energy consumption. Again, the activated sludge system presents the highest environmental burden in the global warming category, when compared to the other systems, due to the high energy input for aeration. The constructed wetland and in particular the slow rate infiltration have sig- 

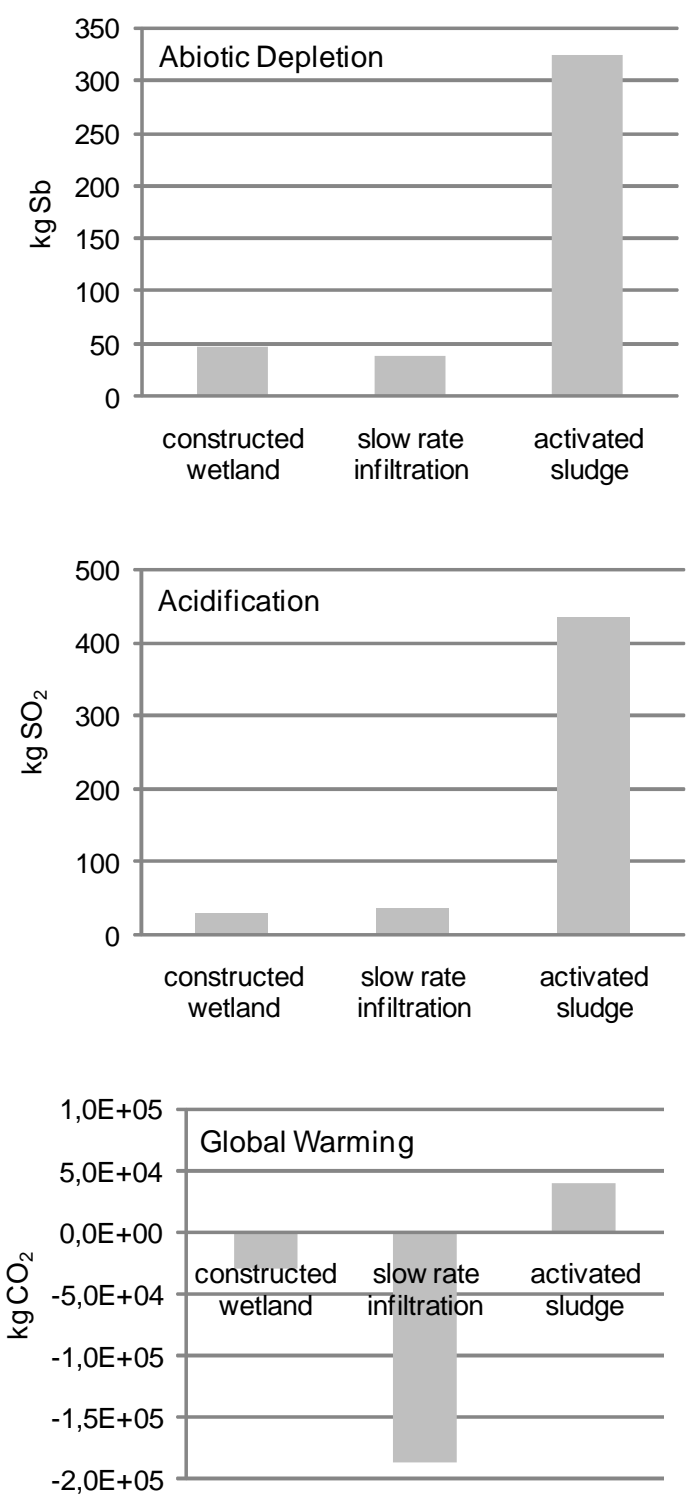

Fig. 5. Inventory results per impact category expressed in relation to a functional unit of 1 p.e.

nificantly lower overall $\mathrm{CO}_{2}$ emissions, due to the fact that biomass acts as a carbon sink, locking away atmospheric carbon.

The main sources of solid emission resulted from the land excavated during construction and from the surplus sludge production during system operation. Dixon et al. [5] reported that the environmental impact of soil removal can be reduced by their reuse in the infill during the dismantling phase. Sludge spreading on soil was the procedure applied by Lundin et al. [1] in order to reduce environmental impact of sludge disposal. Such a procedure can only be considered in non sensitive areas and might be questionable when large quantities are disposed off. The reuse of sludge is translated into a reduc- tion in the abiotic depletion impact of constructed wetland and activated sludge systems.

The activated sludge system presents the highest impact in the impact category acidification derived from the combustion of fossil fuels to produce electricity with the consequent release of acid gases.

Options for reduction of life cycle impacts were assessed including materials used in construction and operation lifetime of the systems. A $10 \%$ extension of operation lifetime of constructed wetland and slow rate infiltration systems lead to a 5\% and 7\% decrease in the abiotic depletion indicator, respectively, and to a $1 \%$ decrease in $\mathrm{CO}_{2}$ emissions in both systems. The effect of the materials used in the construction of activated sludge and Imhoff tanks (used as a pre-treatment in the constructed wetland), respectively steel and concrete, on the life cycle impact of the systems was assessed. In both units steel and concrete were substituted by HDPE, a material that can be used in construction. Replacing steel with HDPE in the activated sludge tank resulted in a 1\% reduction in $\mathrm{CO}_{2}$ emission and $1 \%$ in the abiotic depletion category considering a functional unit of 1 p.e. In the case of the Imhoff tank a $1 \%$ reduction in $\mathrm{CO}_{2}$ emissions and $5 \%$ in the abiotic depletion category were observed when concrete was replaced by HDPE.

\section{Conclusions}

The costs of construction, operation and maintenance of the several energy-saving wastewater treatment systems audited during the project were very competitive, namely when compared to intensive conventional systems. Additionally, because noise problems are minimized and landscape value and scenic quality are preserved, social acceptance tends to be high. Therefore, such wastewater treatment processes are good examples of sustainable technologies for environmental protection and resources valorization.

The present study reveals that the LCA approach can be used as a decision tool in design studies. The LCA quantification identified the constructed wetland and the slow rate infiltration systems as appropriate technologies in rural areas. The key factor was the reduction of global warming impact due to carbon sequestration, as opposed to the activated sludge processes, which require a high energy input and present a negative carbon balance.

The benefits of low energy consumption wastewater treatment technologies should not be generalized since costs are affected by many factors (e.g. materials used in construction, price of land and labor) and can vary considerably. Also, environmental impact assessment results based on life cycle analysis depend on the processes included in the system boundary and on the materials used in construction. 


\section{Acknowledgments}

This work was supported by EU Program INTERREG III-B Atlantic Arc, Depuranat project (No. 54).

\section{References}

[1] M. Lundin, M. Bergtsson and S. Molander, Life cycle assessment of wastewater systems: Influence of system boundaries and scale on calculated environmental loads, Environ. Sci. Technol., 34 (2000) 180-186.

[2] I. García, J. Rodríguez, J. Rodríguez, B. Suárez, J. Bocardo and N. Martín, Guia sobre tratamientos de aguas residuales urbanas para pequeños núcleos e población, Instituto Tecnologicos das Canarias, Spain, 2006, pp. 55-101.

[3] R.H.C. Emmerson, G.K. Morse, J.N. Lester and D.R. Edge, Lifecycle analysis of small-scale sewage treatment processes, J. Chart. Inst. Water Environ. Manag., 9 (1995) 317-325.

[4] F.J. Dennison, A. Azapagic, R. Clift and J.S. Colbourne, Life cycle assessment: comparing strategic options for the mains infrastructure - Part I, Wat. Sci. Tech., 39 (1999) 315-319.

[5] A. Dixon, M. Simon and T. Burkitt, Assessing the environmen- tal impact of two options for small scale wastewater treatment: comparing a reedbed and an aerated biological filter using a life cycle approach, Ecol. Eng., 20 (2003) 297-308.

[6] R. Nogueira, I. Ferreira, J. Janknecht, J.J. Salas, P. Oliveira and A.G. Brito, Energy-saving wastewater treatment systems: formulation of cost functions, Wat. Sci. Tech., 56 (2007) 85-92.

[7] A.P. Machado, L. Urbano, A.G. Brito, J. Janknecht, J.J. Salas and R. Nogueira, Life cycle assessment of wastewater treatment options for small and decentralized communities: energy-saving systems versus activated sludge, Wat. Sci. Tech., 56 (2007) 15-22.

[8] Introduction to LCA with SimaPro. Pré-product Ecology Consults, 2004.

[9] J.J. Salas, Natural Wastewater Treatment Systems, Centro de las Nuevas Tecnologias del Agua - CENTA, Sevilla, Spain, 2004.

[10] Office Internacional de l'Eau, Document de travail - Project DEPURANAT - Les tecniques d' epuration naturelle: 50 à 200 eh, 2004.

[11] D. Rousseau, Performance of constructed treatment wetlands: model-based evaluation and impact of operation and maintenance, PhD thesis, Ghent University, Belgium, 2005.

[12] C. Boutin, P. Duchène and A. Liénard, Filières d'épuration adaptées aux petites collectivités, Document technique FNDAE n²2, Ed. CEMAGREF, France, 1998. 